\title{
CHST6 mutation screening and endoplasmatic reticulum stress in macular corneal dystrophy
}

\author{
Liyuan Wang ${ }^{1}$, Xianling Tang ${ }^{1}$, Xiaolin Lv ${ }^{1}$, Encheng Sun ${ }^{3}$, Donglai $\mathbf{W u}^{3}$, Changlin \\ Wang $^{2}$ and Ping Liu ${ }^{1}$ \\ ${ }^{1}$ Eye Hospital, The First Affiliated Hospital of Harbin Medical University, Harbin 150001, China \\ ${ }^{2}$ Department of Urology, The First Affiliated Hospital of Harbin Medical University, Harbin 150001, China \\ ${ }^{3}$ State Key Laboratory of Veterinary Biotechnology, Harbin Veterinary Research Institute, Chinese Academy of Agricultural \\ Sciences, Harbin 150069, China
}

Correspondence to: Ping Liu, email: pingliu53@126.com

Keywords: CHST6; macular corneal dystrophy; endoplasmic reticulum stress; apoptosis; keratocytes

Received: August 24, $2017 \quad$ Accepted: September 20, $2017 \quad$ Published: October 24, 2017

Copyright: Wang et al. This is an open-access article distributed under the terms of the Creative Commons Attribution License 3.0 (CC BY 3.0), which permits unrestricted use, distribution, and reproduction in any medium, provided the original author and source are credited.

\section{ABSTRACT}

Macular corneal dystrophy (MCD) is an autosomal recessive disorder mainly caused by gene mutations of carbohydrate sulfotransferase (CHST6) leading to bilateral visual impairment. Because the mechanism underlying this degeneration remains poorly understood, we investigated molecular alterations and pathways that may be involved in MCD in this issue. Different mutation sites were screened by direct sequencing of the coding region of CHST6. In addition, we described morphological changes in MCD keratocytes by light microscopy and electron microscopy and determined the relationship between the development of this disease and the occurrence of apoptosis through flow cytometry, cell counting kit-8, colony formation assay and other experiments. Western blotting and quantitative real-time polymerase chain reaction were used to determine if endoplasmic reticulum (ER) stress was activated. We found $\mathbf{1 0}$ kinds of mutations among these families with 3 novel mutations included. The percentage of apoptotic keratocytes increased in MCD patients; furthermore, the expression of apoptosis related protein B-cell lymphoma-2 (Bcl-2) was down-regulated while $\mathrm{Bcl}-2$ associated $X$ protein was upregulated. Finally, ER stress was activated with the upregulation of glucose-regulated protein 78 and CCAAT-enhancer-binding protein homologous protein. Our clinical and in vitro results suggest that the CHST6 mutation associated with MCD is associated with apoptosis, and ER stress is probably involved in this apoptosis pathway.

\section{INTRODUCTION}

Macular corneal dystrophy (MCD; MIM \#217800) is a rare autosomal recessive disorder that usually becomes evident in childhood or adolescence and is clinically characterized by the formation of a diffuse and fine symmetric clouding in the central corneal stroma that extends to the periphery and eventually involves the entire thickness of the cornea, leading to severe bilateral visual disturbance [1, 2]. Currently, corneal transplantation, including penetrating and lamellar keratoplasty, is still the most effective treatment in MCD patients. There are 3 subtypes of MCD (I, IA and II) subdivided by immunoassay and immunohistochemical studies based on the reactivity against an anti-keratan sulfate (KS) antibody (5-D4 anti-KS antibody, AgKS) in the serum and corneal tissues. In type I MCD, AgKS is absent from both serum and corneal tissues, and in type IA MCD, keratocytes manifest AgKS reactivity only. In type II MCD, AgKS reacts positively both to corneal tissues and to serum with normal or subnormal levels [3-5]. 
Mutations in the carbohydrate sulfotransferase (CHST6, OMIM 605294) gene on chromosome 16q22 encoding corneal glucosamine $\mathrm{N}$-acetyl-6-sulfotransferase (C-GlcNAc6ST), an enzyme that transfers sulfate to the unsulfated keratan chains, have been identified as the cause of MCD in humans [6]. With decreased activity of C-GlcNAc6ST, the poorly sulfated or non-sulfated KS is deposited in the intracellular and extracellular matrix of the cornea among MCD patients. Because the sulfation of carbohydrates greatly influences corneal hydration, poorly sulfated and non-sulfated KS loses its hydrophilicity, contributing to corneal opacity and therefore resulting in a loss of visual acuity $[7,8]$. Sulfotransferases utilize 3'-phospho-5'-adenylyl sulfate (PAPS) as a sulfonate donor to catalyze the transfer of sulfate to position 6-O of the $\mathrm{N}$-acetyl-glucosamine of keratan in the cornea [6, 9-11]. Mutations in C-GlcNAc6ST domains, such as the 5'PB domain, an essential part of the active site responsible for PAPS binding, seriously effect sulfotransferase activity [12-14].

An increase in apoptotic keratocytes was found in patients' cornea tissues with macular dystrophy by immunocytochemical analysis of terminal deoxynucleotidyl transferase-mediated dUTP-biotin nick end labeling (TUNEL) assay [15]. Furthermore, apoptotic activity was also detected in epithelial and endothelial cells. In addition, a very low number of $\mathrm{p} 21$ positive keratocytes were detected in macular dystrophy corneas but absent in normal cornea tissues [16]. However, the molecular mechanisms and pathways that are triggered result in increased apoptotic keratocyte numbers and remain poorly understood.

According to transmission electron microscopy results, corneas with macular dystrophy revealed a continuous thick basal lamina, and large amounts of characteristic electron-dense and vacuolar deposits were observed in the sub-epithelial stroma [17]. Additionally, the increase in the size of the rough endoplasmic reticulum (ER) was found in keratocytes [18]. The ER is activated by the accumulation of misfolded and unfoldable proteins and the imbalance of $\mathrm{Ca}^{2+}$, subsequently termed the unfolded protein response, leading to the increased expression of ER chaperones, such as glucose-regulated protein 78 (GRP78) [19], and downstream molecules, such as CCAAT-enhancerbinding protein homologous protein (CHOP), a key protein for the ER stress-induced apoptosis [20, 21].

Most studies have shown that B-cell lymphoma-2 (Bcl-2) family members control the concentration of ER $\mathrm{Ca}^{2+}$ to regulate apoptosis. Bcl-2 was specifically considered an important anti-apoptotic protein regulating the $\mathrm{ER} \mathrm{Ca}^{2+}$ concentration. In contrast, Bcl-2 associated $\mathrm{X}$ protein (Bax) is an important pro-apoptotic protein localized to both mitochondria and the ER, and it promotes $\mathrm{Ca}^{2+}$ mobilization from the ER to mitochondria during apoptosis [22-27]. The high expression of CHOP inhibits the expression of Bcl-2, in turn destroying the ratio of Bcl2/Bax to induce apoptosis [28].

In this study, we identified the underlying genetic defect in 10 Chinese families affected by MCD by undertaking mutation screening of the CHST6 gene. We identified 3 novel mutations and 7 previously reported mutations consisting of deletions, insertions, missense mutations, and nonsense mutations. We also analyzed the morphology of keratocytes in normal and MCD corneal tissues. In addition, apoptosis and ER stress was further verified in keratocytes with MCD.

\section{RESULTS}

\section{DNA Analysis}

Twenty-one affected patients representing 10 distinct genetic families were enrolled in the study. Direct sequencing of the CHST6 gene from patients with MCD was performed, and 3 novel and 7 previously reported mutations were identified (Table 1). Seven kinds of single base changes and 3 different frame shifts in the coding region of CHST6 were found in this study; only 2 of them were homozygous. Fifty control chromosomes were analyzed for each alteration by direct sequencing of PCR products, and none of the mutations were found among them. Anterior segment photography showed a number of round gray-white deposits that were diffusely distributed in the corneal stroma in almost all families (Figure 1).

Patient 1 (Figure 1A) was homozygous for the transition c.382 G>A, which encodes a missense alanineto-threonine substitution at codon 128 (p.A128T) in family 1 (Figure 2A), and Patient 5 was homozygous for the transition c. $1072 \mathrm{~T}>\mathrm{C}$, resulting in a tyrosine-to-histidine substitution at codon 358 (p.Y358H) in family 5 (Figure 2H).

Patient 2-1 and patient 2-2 were analyzed in family 2 (Figure 1B). Two compound frame shift changes were identified by sequencing. The results showed an insertion of a single base pair between nucleotides 290 and 291, resulting in a frame shift after codon S98 (p.S98Lfs) (Figure 2C). Another frameshift mutation was found after codon 20, depending on a base pair insertion of adenine (insA) after the transversion of thymine to guanine at nucleotide position 62 (c.62 $\mathrm{T}>\mathrm{G}$ ) (Figure 2B).

Both the brother and sister of family 6 inherited MCD and showed the same symptoms. The brother underwent penetrating keratoplasty because of numerous spot deposits diffused on all layers of the cornea; however, the sister only went through lamellar keratoplasty without involving the endothelium layer (Figure 1F). One heterozygous mutation with both a frame shift change and a single base nucleotide change was found in family 6 (denoted the c.463-464 delCG novel variant). These changes result in a frame shift after codon 155 
(p.R155Afs) (Figure 2I) and a single base nucleotide variant c.432 C >A (p.S144R) (Figure 2J).

Furthermore, heterozygosity with compound single base nucleotide changes was detected in 6 other families. In family 3 , irregular large spots were seen in the proband's cornea (Figure 1C), and a heterozygous change, c.418 C>T (Figure 2D) and c.613 C $>\mathrm{T}$ (Figure $2 \mathrm{E})$, was identified, predicting amino acid changes of an arginine to a stop codon (p.R140X) and arginine to a tryptophan (p.R205W). Heterozygous mutants including c. $730 \mathrm{G}>\mathrm{T}$ (Figure $2 \mathrm{~K}$ ) and c.1072 $\mathrm{T}>\mathrm{C}$ (Figure 2L), which predicted amino acid changes of arginine to a stop codon (p.E244X) and tyrosine to histidine (p.Y358H), respectively, were identified in family 7 (Figure $1 \mathrm{G}$ ). In addition, a heterozygous change, c.418 $\mathrm{C}>\mathrm{T}$ (Figure $2 \mathrm{~F}$ ) and c.1072 $\mathrm{T}>\mathrm{C}$ (Figure $2 \mathrm{G}$ ), resulting in glutamine and tyrosine changing to a stop codon (p.R140X) and histidine (p.Y358H), respectively, was found in family 4 (Figure 1D). Additionally, a heterozygous change, c.892 $\mathrm{C}>\mathrm{T}$ (Figure $2 \mathrm{M}$ ) and c.1072 $\mathrm{T}>\mathrm{C}$ (Figure $2 \mathrm{~N}$ ), leading to amino acid changes of glutamine to a stop codon (p.Q298X) and tyrosine to histidine (p.Y358H), was detected in family 8 (Figure $1 \mathrm{H}$ ).
In families 9 and 10, only one heterozygous pathogenic change was observed in the coding CHST6 sequence. We found c.1072 $\mathrm{T}>\mathrm{C}$, which changes a tyrosine to a histidine (p.Y358H) in patient 9 with white spots developing in sheets in the cornea (Figure 1I). Additionally, c.892 C>T was found in family 10 , changing a glutamine to a stop codon substitution (p.Q298X).

When the pathogenic effect of the novel missense variation was evaluated with SIFT and PolyPhen-2 in silico analysis software, the results were "probably damaging" and "affect protein function," respectively (Table 1). The 3 novel mutations including missense and frameshift variations were also tested with MutationTaster, which predicted "disease causing". Additionally, all newly detected variants in the CHST6 gene were not found in 50 control chromosomes, 1,000 Genomes (1000G), Exome Aggregation Consortium (ExAC), and the Human Gene Mutation Database (HGMD). Furthermore, amino acid sequence analyses between humans and other mammals revealed that the amino acids substituted in the missense variation detected in the patients were highly conserved residues.

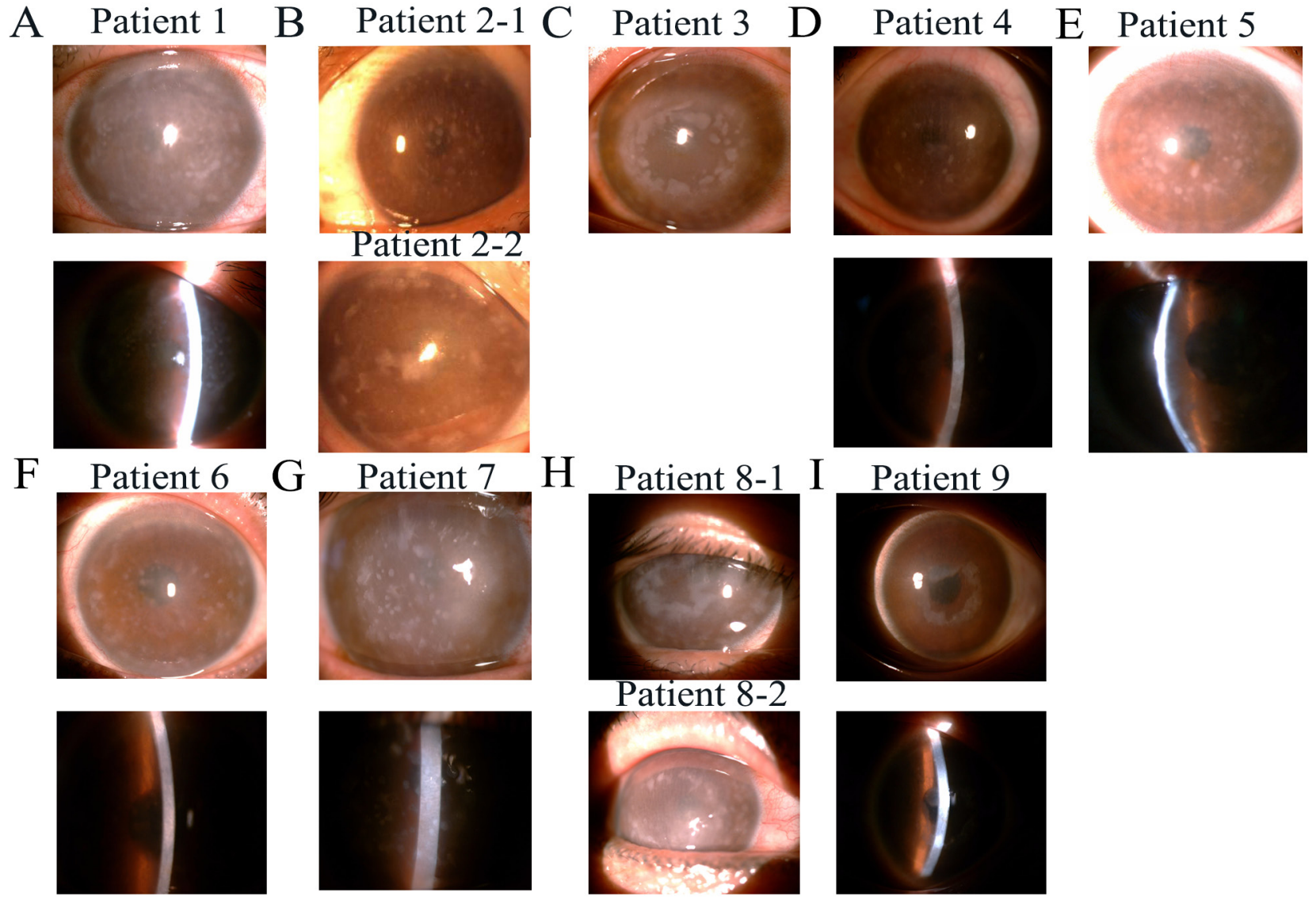

Figure 1: Slit-lamp photographs of patients from nine families with macular corneal dystrophy (MCD). (A-I) Showing multiple, irregular gray-white hazes diffused on the central and peripheral cornea. Photograph of family 10 was missing. 
Table 1: Ten mutations of CHST6 among ten unrelated Chinese MCD pedigrees

\begin{tabular}{|c|c|c|c|c|c|c|c|c|c|}
\hline Family & $\begin{array}{c}\text { Number } \\
\text { of } \\
\text { patients }\end{array}$ & Zygosity & $\begin{array}{l}\text { Nucleotide } \\
\text { change }\end{array}$ & $\begin{array}{l}\text { Protein } \\
\text { change }\end{array}$ & $\begin{array}{c}\text { Mutation } \\
\text { type }\end{array}$ & PolyPhen & SIFT & $\begin{array}{c}\text { HGMD } \\
\text { NO }\end{array}$ & $\begin{array}{c}\text { Mutation } \\
\text { Taster }\end{array}$ \\
\hline 1 & 2 & Homozygous & c. $382 \mathrm{G}>\mathrm{A}$ & p. A128T & Missense & $\begin{array}{c}0.945 / \\
\text { Possibly }\end{array}$ & 0 & Novel & $\mathrm{DC}$ \\
\hline \multirow[t]{2}{*}{2} & 3 & Heterozygous & $\begin{array}{c}\text { c. 61-62ins A, } 62 \\
\quad T>G\end{array}$ & p. L20R fs & $\begin{array}{l}\text { Frameshift } \\
\text { mutation }\end{array}$ & MD & MD & Founder & $\mathrm{DC}$ \\
\hline & & & c. $290-291$ ins G & p. S98L fs & $\begin{array}{c}\text { Frameshift } \\
\text { mutation }\end{array}$ & MD & MD & Novel & $\mathrm{DC}$ \\
\hline \multirow[t]{2}{*}{3} & 3 & Heterozygous & c. $418 \mathrm{C}>\mathrm{T}$ & p. R140X & Missense & MD & MD & CM050195 & $\mathrm{DC}$ \\
\hline & & & c. $613 \mathrm{C}>\mathrm{T}$ & p. R205W & Missense & $\begin{array}{c}1.0 / \\
\text { Possibly } \\
\text { damaging }\end{array}$ & 0 & CM104650 & $\mathrm{DC}$ \\
\hline \multirow[t]{2}{*}{4} & 1 & Heterozygous & c. $418 \mathrm{C}>\mathrm{T}$ & p. R140X & Missense & MD & MD & CM050195 & $\mathrm{DC}$ \\
\hline & & & c. $1072 \mathrm{~T}>\mathrm{C}$ & p. Y358H & Missense & $\begin{array}{c}1.0 / \\
\text { Possibly } \\
\text { damaging }\end{array}$ & 0 & CM092026 & DC \\
\hline 5 & 1 & Homozygous & c. $1072 \mathrm{~T}>\mathrm{C}$ & p. Y358H & Missense & $\begin{array}{c}1.0 / \\
\text { Possibly } \\
\text { damaging }\end{array}$ & 0 & CM092026 & $\mathrm{DC}$ \\
\hline \multirow[t]{2}{*}{6} & 2 & Heterozygous & c. $432 \mathrm{C}>\mathrm{A}$ & p. S144R & Missense & $\begin{array}{c}0.961 / \\
\text { Possibly } \\
\text { damaging }\end{array}$ & 0.07 & CM104653 & $\mathrm{DC}$ \\
\hline & & & c. $463-464 \mathrm{del} C G$ & p. R155Afs & $\begin{array}{c}\text { Frameshift } \\
\text { mutation }\end{array}$ & MD & MD & Novel & DC \\
\hline \multirow[t]{2}{*}{7} & 3 & Heterozygous & c. $730 \mathrm{G}>\mathrm{T}$ & p. E244X & Missense & MD & MD & CM104646 & DC \\
\hline & & & c. $1072 \mathrm{~T}>\mathrm{C}$ & p. Y358H & Missense & $\begin{array}{c}1.0 / \\
\text { Possibly } \\
\text { damaging }\end{array}$ & 0 & CM092026 & $\mathrm{DC}$ \\
\hline \multirow[t]{2}{*}{8} & 3 & Heterozygous & c. $1072 \mathrm{~T}>\mathrm{C}$ & p. Y358H & Missense & $\begin{array}{c}1.0 / \\
\text { Possibly } \\
\text { damaging }\end{array}$ & 0 & CM092026 & $\mathrm{DC}$ \\
\hline & & & c. $892 \mathrm{C}>\mathrm{T}$ & p. Q298X & Missense & MD & MD & CM092027 & $\mathrm{DC}$ \\
\hline 9 & 2 & Heterozygous & c. $892 \mathrm{C}>\mathrm{T}$ & p. Q298X & Missense & MD & MD & CM092027 & DC \\
\hline 10 & 1 & Heterozygous & c. $1072 \mathrm{~T}>\mathrm{C}$ & p. Y358H & Missense & $\begin{array}{c}1.0 / \\
\text { Possibly } \\
\text { damaging }\end{array}$ & 0 & CM092026 & $\mathrm{DC}$ \\
\hline
\end{tabular}

Predictions and scores estimated with the SIFT, PolyPhen-2 and mutation taster2. MD: must damaging, DC: disease causing.

\section{Histologic and ultrastructural changes in corneas with MCD}

By light microscopy, there were great changes in the morphology and structure of the epithelium and stroma between the MCD and normal corneas. The epithelium of corneas with deposit areas was thin and irregularly arranged, decreasing from 5-6 to 3-4 cell layers. On the other hand, the disordered arrangement of collagen fiber and increased density of keratocytes were seen in the subepithelial and upper layer of the stroma according to the hematoxylin and eosin staining results (Figure 3A). In five corneal buttons with macular dystrophy, PAS and Alcian blue staining revealed typical polysaccharide 
sulfate deposits intracellular and extracellular in the subepithelial layer and stroma (Figure 3B, 3C). By transmission electron microscopy, in the stroma of MCD corneas, a large number of electron dense granules were deposited in the cytoplasm of the keratocytes with a large number of the rough ER surrounded (Figure 3D), which was not detected in the normal stroma.

\section{Characterization of MCD keratocytes}

The morphological changes between WT and MCD keratocytes were analyzed by phase contrast microscopy. Through comparative analysis, MCD keratocytes were larger in size, and showed a senescence-like morphology, which was not seen in WT keratocytes (Figure 4A). These morphological abnormalities often suggested that certain pathological changes occurred on MCD keratocytes due to the mutations. Ultrastructural analyses using electron microscopy were used to reveal characteristics of the apoptotic MCD keratocytes in which cells became crinkled, chromatin aggregated and apoptotic bodies formed (Figure 4B).

\section{Keratocyte proliferation and apoptosis in MCD}

The primary cultured WT and MT keratocytes subcultured for 6-10 generations were used for flow cytometry. The MT group exhibited an increase in apoptotic cells (Figure 4C). Furthermore, cell proliferation assays showed that the growth in MCD keratocytes was inhibited significantly compared with the normal keratocytes (Figure 4D). We also did a clonogenic assay and found that clone numbers in the MCD keratocytes were reduced significantly (Figure 4E).

\section{ER stress in response to mutation of CHST6 in MCD keratocytes}

We proposed that apoptosis occurred by the activation of ER stress in MCD keratocytes. To assess the

\section{Family $1 \quad$ Family 2}

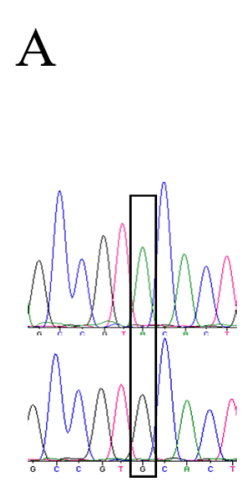

c. $382 \mathrm{G}>\mathrm{A}$

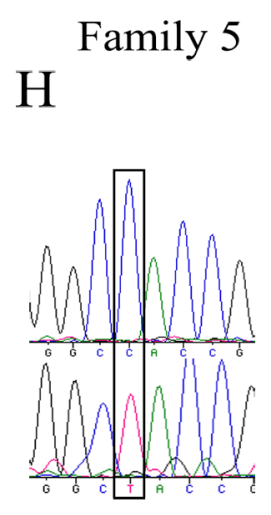

c. $1072 \mathrm{~T}>\mathrm{C}$

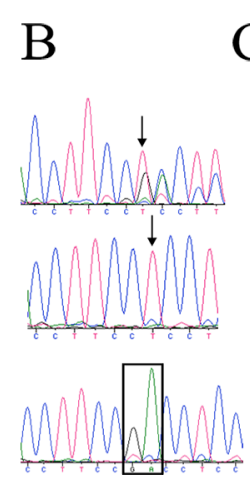
c. $61-62$ ins $A$,
$\quad 61 T>G$
C
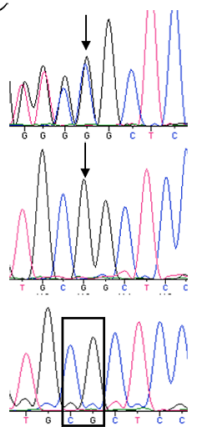

c. $290-291 \mathrm{insG}$

Family 6

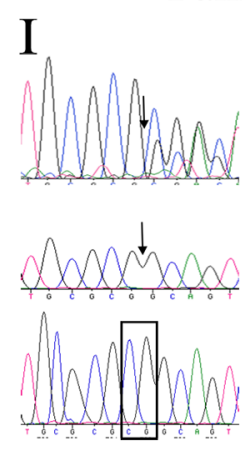

c. $463-464 \mathrm{delCG}$

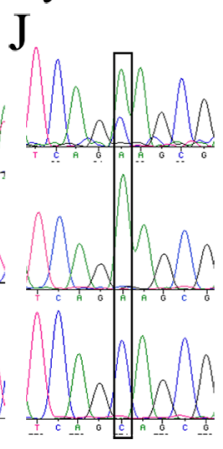

c. $432 \mathrm{C}>\mathrm{A}$

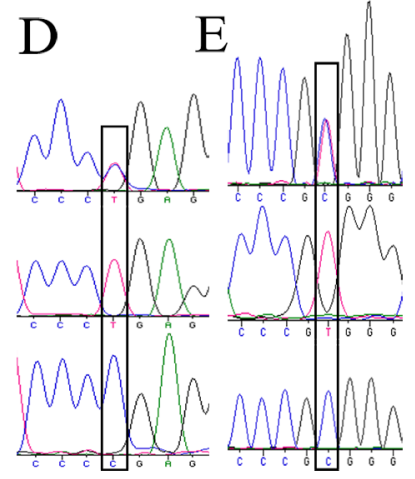

c. $418 \mathrm{C}>\mathrm{T} \quad$ c. $613 \mathrm{C}>\mathrm{T}$
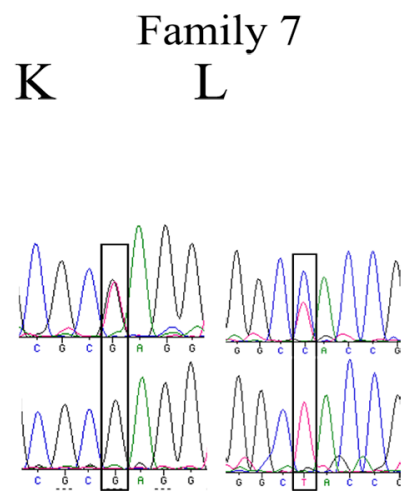

c. $730 \mathrm{G}>\mathrm{T}$
Family 3

F $\quad$ G

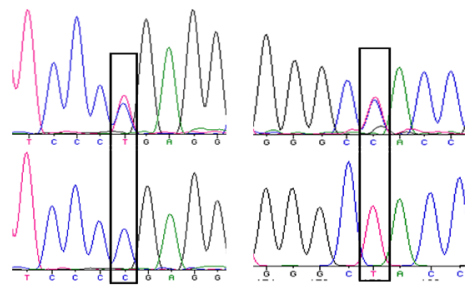

c. $418 \mathrm{C}>\mathrm{T} \quad$ c. $1072 \mathrm{~T}>\mathrm{C}$
Family 8

M
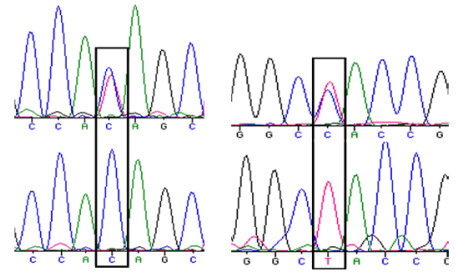

c. $892 \mathrm{C}>\mathrm{T}$

c. $1072 \mathrm{~T}>\mathrm{C}$

Figure 2: Sequencing chromatograms of variations in CHST6 identified in this study. (A) Sequence chromatograms showing one novel homozygous missense mutation in family 1, c.382 G>A. (B-G, I-N) sequences of the open reading frame of CHST6 from heterozygous mutation families were subcloned into $\mathrm{p} 3 \mathrm{xFLAG-CMV10}$ vectors and directly sequenced for heterozygous mutation analysis. (H) One founder homozygous missense mutation in family 5, c.1072 T>C. 
A

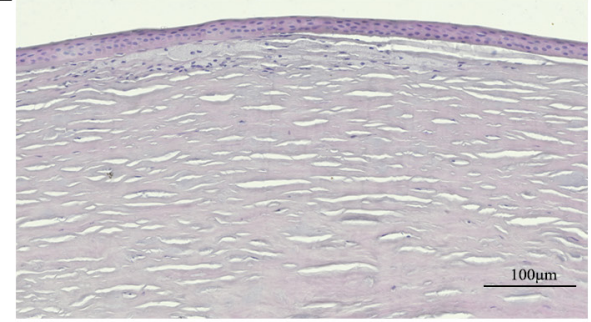

$\mathrm{C}$

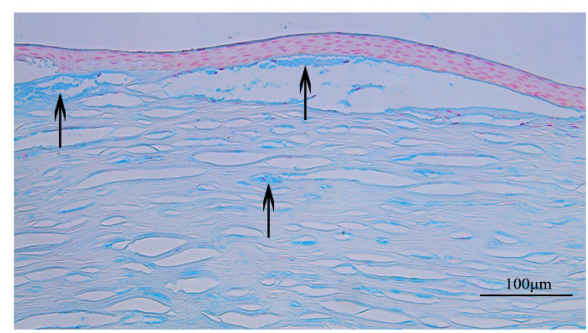

$\mathrm{B}$

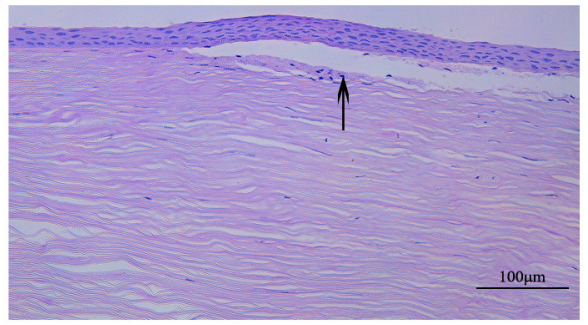

$\mathrm{D}$

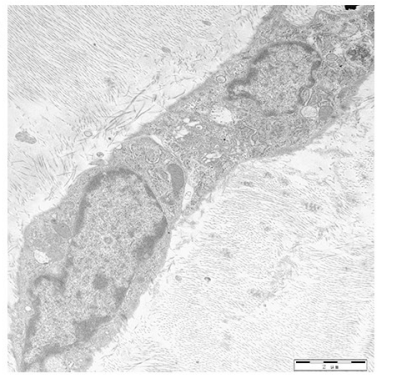

WT

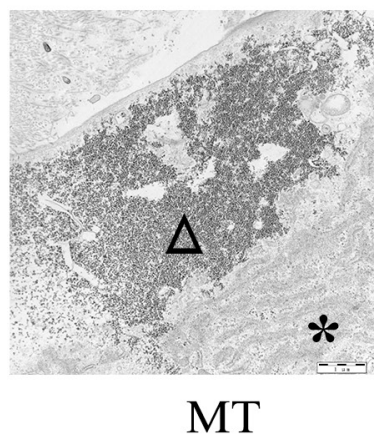

Figure 3: Pathological changes of MCD tissues observed by histologic and ultrastructural analysis. (A) Subepithelial collagen fibers showed irregularity with hyalin deposited, stained with hematoxylin and eosin. (B-C) PAS and Alcian blue stain showed abnormal accumulations in the subepithelial and upper layer of the stroma. (D) Ultrastructural analysis showed that a large number of electron dense deposits are deposited in the corneal stroma with activated rough ER. Arrows show the polysaccharide sulfate deposits. The asterisked triangle represents the rough ER. Triangles indicate the electron dense deposits.

A

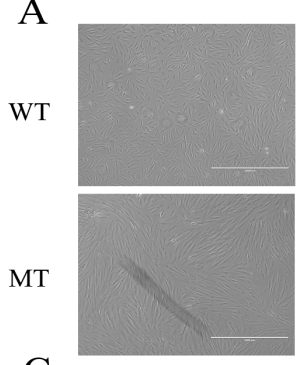

C
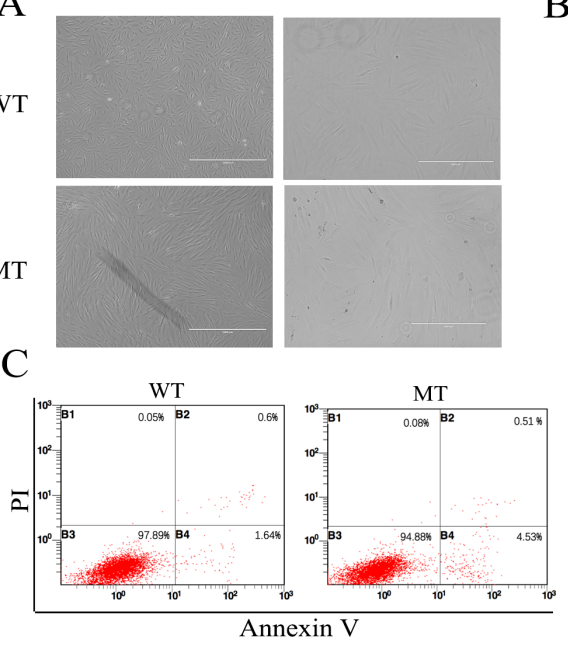

$\mathrm{D}$

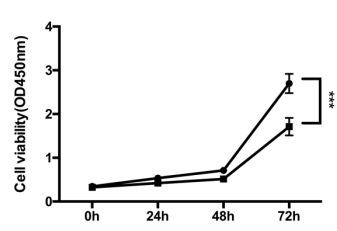

B

WT
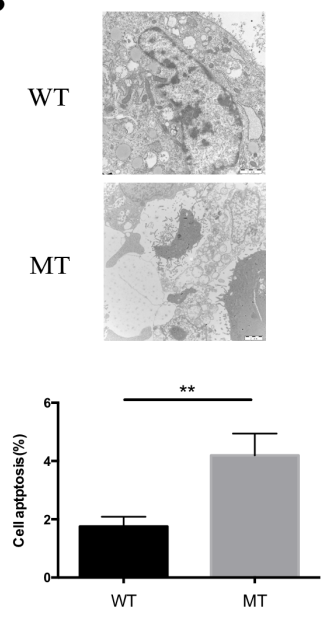

$\mathrm{E}$

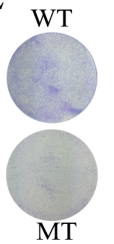

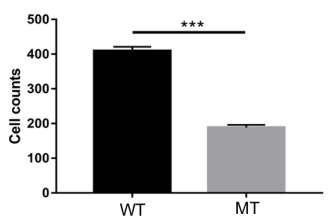

Figure 4: The changes in proliferation and apoptosis in MCD keratocytes. (A) Keratocytes from patients were larger, longer and included more sick cells. (B) Characterization of apoptosis of MCD keratocytes analyzed by transmission electron microscope examination. Concentration of encapsulated cells, chromosome aggregation and apoptosis body formation are shown. (C) Flow cytometry results show that the percentage of apoptotic cells increased in the MT group. (D-E) Cell proliferation and clonogenic assays illustrated that keratocytes of MT had better cell viability and a stronger ability to form clones than WT. Statistical analysis between the two groups were analyzed by t-test, in which a $\mathrm{p}$-value of less than 0.05 was considered statistically significant $\left({ }^{* *} \mathrm{p}<0.01,{ }^{* * *} \mathrm{p}<0.001\right)$. 

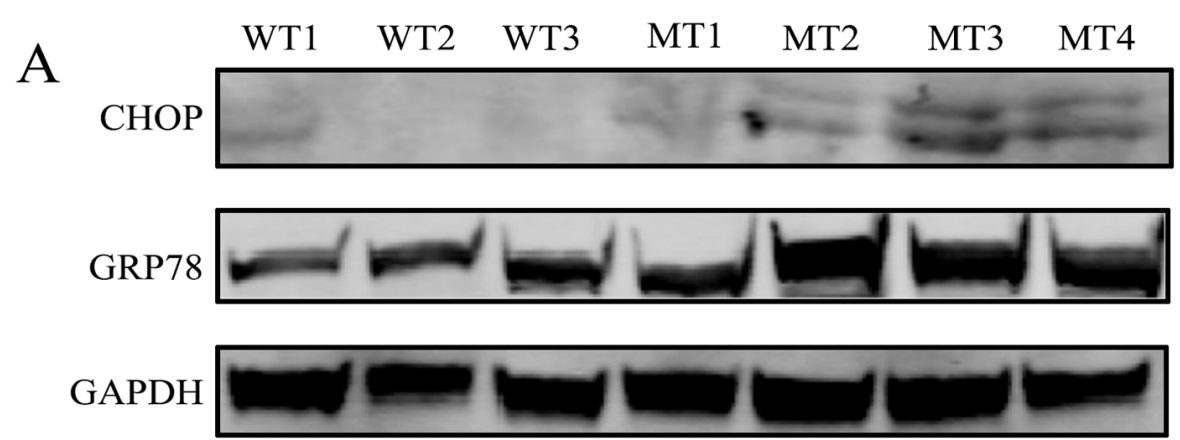

B

$\mathrm{Bcl}-2$

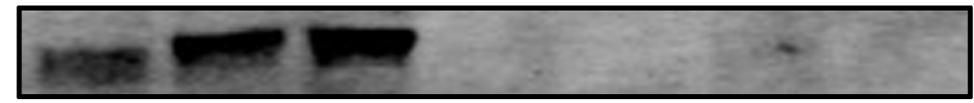

$\operatorname{Bax}$

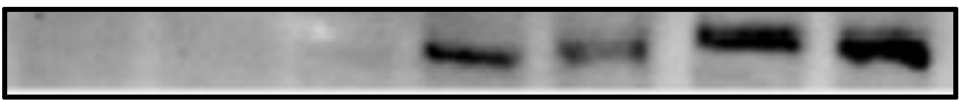

GAPDH

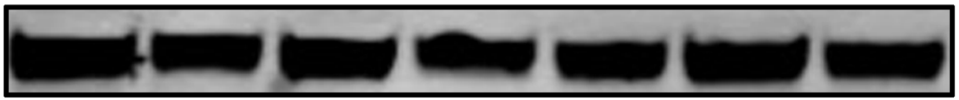

C

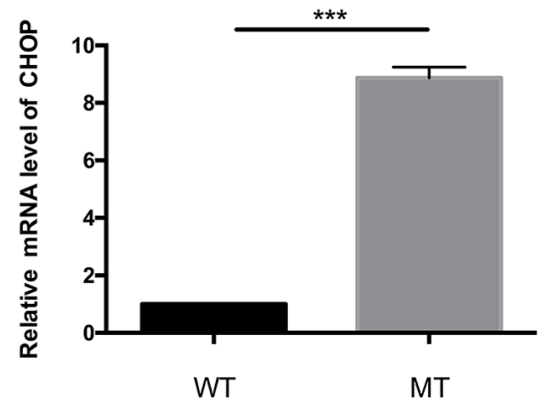

$\mathrm{E}$

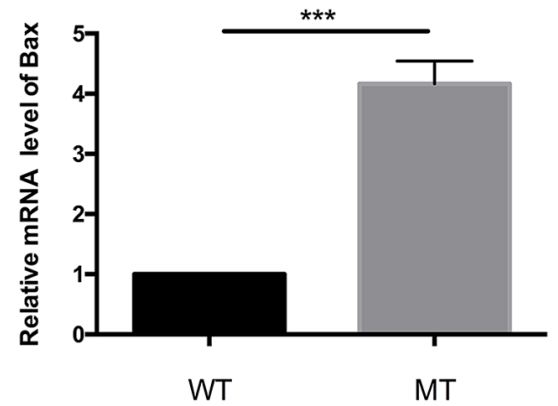

$\mathrm{D}$

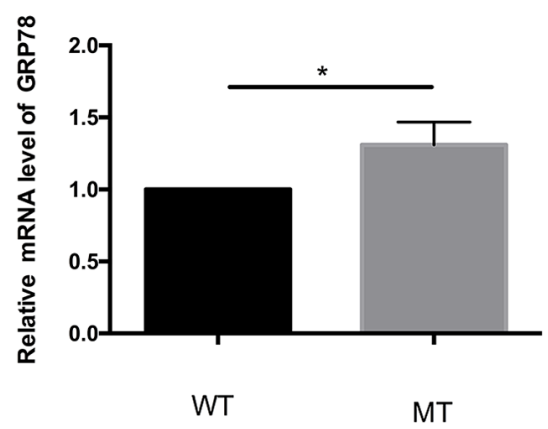

$\mathrm{F}$

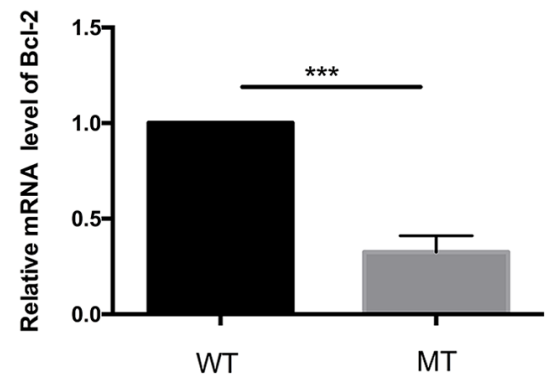

Figure 5: Expression of regulation proteins of apoptosis and ER stress pathways in WT and MT keratocytes. (A) Expression of CHOP, an ER stress-associated transcription factor, and GRP78, an ER chaperone. (B) Expression of Bcl-2 family proteins in WT and MT keratocytes. Bcl-2 was downregulated, but Bax was upregulated. (C-F) Relative mRNA levels of CHOP, GRP78, Bcl-2 and Bax. Only Bcl-2 was decreased ( $\left.{ }^{*} \mathrm{p}<0.05,{ }^{* * *} \mathrm{p}<0.001\right)$. 
effects of ER stress in MCD keratocytes, we detected the expression of GRP78 by western blotting and qPCR. As depicted, GRP78 was significantly upregulated in MCD keratocytes, compared to the control (Figure 5A, 5D). We then verified the expression of $\mathrm{CHOP}$, a key protein for ER stress-induced apoptosis, through western blotting and real-time PCR. The results clearly showed that CHOP was upregulated in MCD keratocytes according to statistical analysis (Figure 5A, 5C). Finally, changes in Bcl-2 and Bax were compared to verify if apoptosis occurred in keratocytes with CHST6 mutations. It appeared that Bcl-2 levels were much lower in MCD cells than in normal cells (Figure 5B, 5F). In contrast to the attenuated expression of Bcl-2, that of Bax, a pro-apoptotic protein, was enhanced in MCD keratocytes (Figure 5B, 5E).

\section{DISCUSSION}

In this study, we report the mutation screening of the CHST6 gene in 10 Chinese families with MCD. Ten independent mutations, seven missense, two insertions and one deletion were identified. Of these, three were novel, whereas the others were founded previously in MCD patients [14]. Furthermore, we preliminary

Family 1

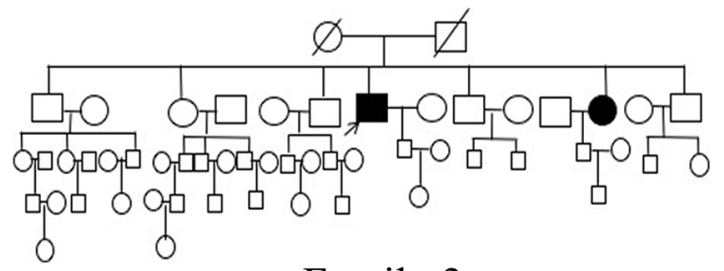

Family 3

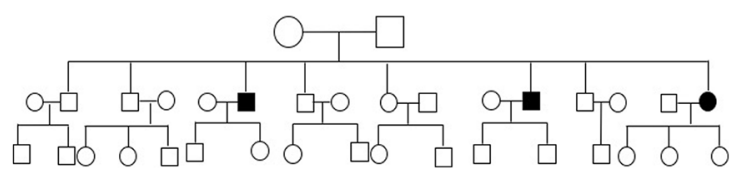

Family 6

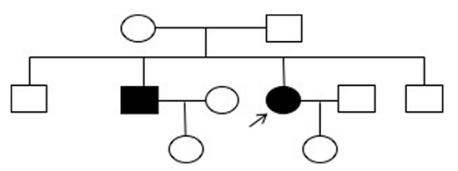

Family 8

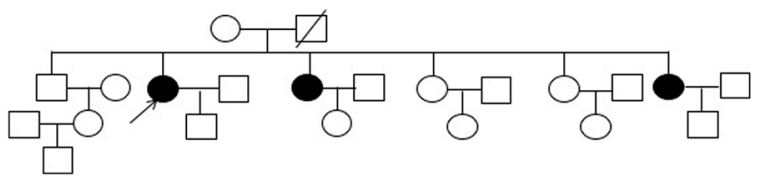

investigated the role of ER stress and apoptosis in MCD keratocytes.

Genetic mutations at different sites most likely affect the function of the gene, especially at positions in the protein that are highly conserved across carbohydrate sulfotransferases and/or within important domains that are essential for maintaining the structure and function of the protein. For example, the substitution of p.R205W, located within the 5'PB domain, seriously reduces the ability to combine with PAPS. This affects the sulfide transfer function of sulfotransferases $[10,13]$. In addition, 2 missense mutations (p.S144R and p.Y358H) affected enzyme activity and involved the substitution of an uncharged polar residue for a basic residue at a nonconservative or conservative site. Although the previously unreported p.A128T substitution belonged to a chemically similar amino acid, its position was highly conserved in the GlcNAc6ST gene family, such that a mutation at that position makes C-GlcNAc6ST inactive. On the other hand, we have discovered one deletion, two insertions and three nonsense mutations of stop codons. These mutations were all predicted to terminate the translation in advance with premature stop codons. Abnormal mRNAs of GlcNAc6ST, including premature termination codons,
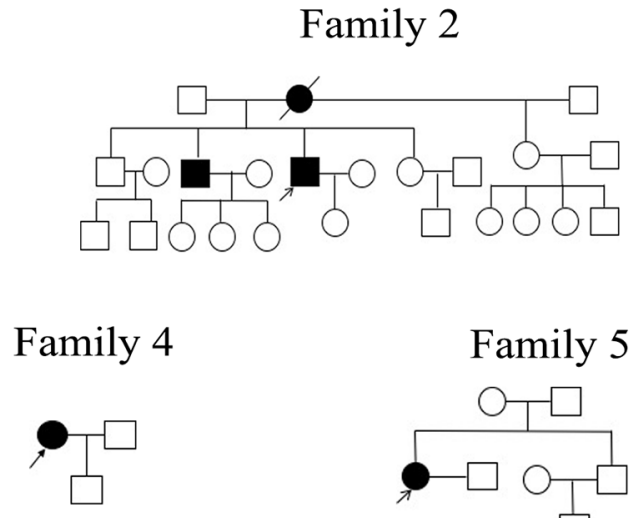

Family 9

Family 7
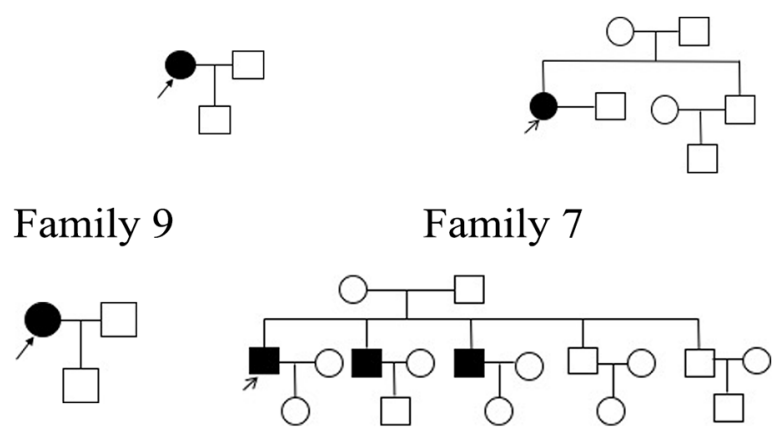

Family 10

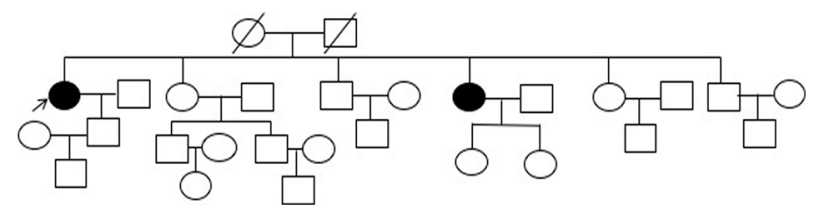

Figure 6: Ten MCD families who participated in the study. Open and closed symbols indicate unaffected and affected individuals, respectively. Deceased family members are denoted by diagonal slashes, the arrow marks the proband in these families. 
are eliminated by the physiological process of nonsensemediated decay [29].

ER stress is a universal physiopathological response to a variety of stimuli that may play a protective role or may induce cell apoptosis independently. Our results showed that the ER stress marker protein GRP78 is upregulated in MCD keratocytes, which shows that the ER stress response is active. On the other hand, the upregulation of GRP78 is a key step leading to subsequent cellular events including cell death $[30,31]$. We confirmed that the expression of CHOP was enhanced by western blotting and real-time PCR (Figure 5). Activated CHOP could influence gene expression related to apoptosis, including decreased Bcl-2 expression [32], which was consistent with our experimental results.

As described by Szentmáry there is a statistically significant increase in apoptotic keratocyte numbers in corneal tissues with macular dystrophy [16]; keratocytes from MCD patients also have this feature verified in this article. In our results, the expression of $\mathrm{Bcl}-2$ was significantly reduced, whereas Bax was increased. The ratio of $\mathrm{Bcl}-2 / \mathrm{Bax}$ decreased significantly in $\mathrm{MCD}$ keratocytes compared with normal cells, thus inducing apoptosis.

In summary, based on our findings, we not only identified 10 mutations including 3 novel mutations but were also able to prove that apoptotic cell death was increased in keratocytes from MCD patients. A striking finding of this study is that mutations in CHST6 may trigger ER stress with considerable GRP78/CHOP upregulation and cell apoptosis, however, the exact molecular mechanisms need to be validated by more experiments. There are no effective treatments for this hereditary MCD except for corneal transplantation. By studying the pathological process of MCD and interfering with the signaling pathway, MCD could be delayed or even blocked.

\section{MATERIALS AND METHODS}

\section{Patients and control subjects}

Twenty-one patients from 10 unrelated families (Figure 6) received clinical diagnoses of MCD by three doctors using slit-lamp biomicroscopy in the First Affiliated Hospital of Harbin Medical University; corneal optical coherence tomography was also analyzed in this study. Control subjects were selected from 50 individuals with no visual impairment. The diagnosis in five patient families was MCD type I. Informed consent was obtained from all patients and their family members in agreement with the Declaration of Helsinki for research involving human subjects. Approvals for genetic testing were obtained from the First Affiliated Hospital of Harbin Medical University.

\section{CHST6 analysis}

Genomic DNA was isolated from peripheral blood leukocytes by standard techniques according to the manufacturer's instructions (Qiagen, USA). Three pairs of primers designed by Akama et al. were used to amplify the region of the open reading frame (ORF) of CHST6 [6]. Each PCR reaction was performed as a $50 \mu \mathrm{l}$ reaction mixture consisting of genomic DNA (100 ng) and $25 \mu \mathrm{l}$ of PrimeSTAR HS Premix DNA polymerase (Takara, Japan) containing PrimeSTAR HS DNA Polymerase, dNTP Mixture and PrimeSTAR HS Buffer. Amplification reactions were performed under the following conditions: 5 min of denaturation at $98^{\circ} \mathrm{C}$ followed by 35 cycles of denaturation at $98^{\circ} \mathrm{C}$ for 10 seconds, annealing for 15 seconds at $55^{\circ} \mathrm{C}$ (for the middle coding region) or at $57^{\circ} \mathrm{C}$ (for the $5^{\prime}$ and $3^{\prime}$ ' coding regions), extension at $72^{\circ} \mathrm{C}$ for 45 seconds, and a further extension step at $72^{\circ} \mathrm{C}$ for $7 \mathrm{~min}$. The PCR products were separated by agarose gel electrophoresis and purified with a kit (Gel Extraction Kit; OMEGA, USA). Bidirectional sequencing was performed by using a DNA sequencer (model 3730; Applied Biosystems, CA, USA). The ORFs of CHST6 of 10 families were cloned into p3xFLAG-CMV10 vector by PCR product using the primers, F: 5'AGTCGAATTC AATGTGGCTGCCGCGCGTC3' and R: 5' ACTGTCTA GACTAATTTCGGGGGTGCGAGGC3'. The resulting plasmid was named p3xFLAG-CHST6. All PCR products and plasmids were sequenced for fidelity.

The pathogenicity of the novel missense variation was evaluated with the SIFT and PolyPhen-2 software programs. Additionally, conservation of the involved amino acids among several kinds of mammals was evaluated using MutationTaster.

\section{Histologic and transmission electron microscopy of corneal tissues and keratocytes}

Corneal buttons obtained from MCD patients who underwent keratoplasty were processed for histologic and transmission electron microscopy (EM) studies. Histologic analysis was performed on $4 \mu \mathrm{m}$ thick sections of paraffinembedded cornea buttons from 5 unrelated MCD patients who underwent keratoplasty. Hematoxylin and eosin (HE), periodic acid-Schiff (PAS), and Alcian blue were used to stain the corneal tissues for light microscopy analysis. In addition, keratocytes and corneal tissues were prepared for thin sectioning. Briefly, the specimen was fixed with $2.5 \%$ (vol./vol.) glutaraldehyde in $0.1 \mathrm{M}$ for $2 \mathrm{~h}$, rinsed with 3 changes of phosphate-buffered saline (PBS; Gibco BRL, Grand Island, NY), and postfixed with $1 \%$ (vol./vol.) $\mathrm{OsO}_{4}$ in PBS for $2 \mathrm{~h}$. After being washed, the specimen was dehydrated in a graded series of ethanol and embedded in epoxy (low-viscosity agar) resin, following the standard protocol. Ultrathin sections were collected on carbon- 
coated 100 mesh copper grids and stained with $1 \%$ uranyl acetate and $1 \%$ lead citrate. EM grids were screened at 80 $\mathrm{kV}$ in a Hitach-H7650 transmission electron microscope.

\section{Culture of primary keratocytes}

Primary keratocytes were acquired from wild type (WT) donors from the Heilongjiang Province Eye Bank and from MCD patients, mutation type group (MT), after penetrating or lamellar keratoplasty. Corneas were washed 3 times, 15 min per time, with $1 \times$ PBS containing 1000 units $/ \mathrm{ml}$ penicillin and $1.0 \mathrm{mg} / \mathrm{ml}$ streptomycin sulfate (Gibco BRL, Grand Island, NY). The corneal epithelium, endothelium, sclera and conjunctiva were removed completely. A quarter of the corneal tissues were cultured on $30-\mathrm{mm}$ culture dishes with $200 \mu \mathrm{l}$ of $10 \%$ fetal bovine serum F12/DMEM containing 1000 units/ml penicillin and $1.0 \mathrm{mg} / \mathrm{ml}$ streptomycin sulfate overnight at $37^{\circ} \mathrm{C}$ in $5 \% \mathrm{CO}_{2}$, followed by incubation in $500 \mu \mathrm{l}$ of medium. The primary keratocytes were subcultured to $90 \%$ confluency in media containing $0.25 \%$ trypsin and $5.0 \mathrm{mmol} / \mathrm{L}$ EDTA.

\section{Flow cytometry and apoptotic analysis}

Annexin V/dead cell apoptosis analysis was performed according to the manufacturer's protocol (Alexa Fluor ${ }^{\circledR} 488$ Annexin V/Dead Cell Apoptosis Kit, Invitrogen, USA). Approximately $1 \times 10^{5}$ keratocytes per well were plated onto $9.6 \mathrm{~cm}^{2}$ cell culture dishes. Then, 18-24 h later, $1 \times 10^{6}$ keratocytes were harvested after washing in cold PBS and re-centrifuged with $100 \mu \mathrm{l} 1 \times$ Annexin-binding buffer. Five microliters of Alexa Fluor ${ }^{\circledR} 488$ Annexin V and $1 \mu \mathrm{l}$ of $100 \mu \mathrm{g} / \mathrm{mL}$ propidium iodide (PI) working solution were then added to each $100 \mu \mathrm{l}$ suspension of keratocytes and incubated at room temperature for $15 \mathrm{~min}$. After incubation, $400 \mu \mathrm{l}$ of $1 \times$ Annexin-binding buffer was added, mixed gently and stored on ice. We analyzed the stained cells by flow cytometry (Cytomics TM FC 500, Beckman Coulter, USA).

\section{Cell proliferation assay}

Cells were detached by treatment with $0.25 \%$ trypsin-EDTA (Invitrogen, Carlsbad, CA, USA) and seeded into 96-well plates at a density of $1 \times 10^{3}$ per well in $100 \mu \mathrm{l}$ of media. For the CCK-8 assay, a Cell Counting Kit-8 (Beyotime, Shanghai, China) was used following the manufacturer's instructions. Briefly, $2 \mathrm{~h}$ before each of the desired time points ( $24 \mathrm{~h}, 48 \mathrm{~h}$ and $72 \mathrm{~h}$ ), the CCK- 8 reagent was added to each well at a dilution of 1:10, and cells were incubated at $37^{\circ} \mathrm{C}$ for $2 \mathrm{~h}$. The absorbance was detected at $450 \mathrm{~nm}$ using a microplate reader (BioTek, VT, United States). All of the experiments were repeated three times.

\section{Clonogenic assay}

For the clonogenic assay, 5000 cells per well were seeded in 6-well plates. Visible colonies were observed using the naked eye 14 days later, fixed with $4 \%$ formaldehyde, and stained with $0.1 \%$ crystal violet. Colonies with a diameter greater than $1 \mathrm{~mm}$ were counted.

\section{Real-time quantitative reverse transcription- PCR}

A two-step reaction process was used for quantification: reverse transcription (RT) and PCR. The ReverTra Ace qPCR RT Kit (TOYOBO, Japan) was used for RT according to the manufacturer's protocols. The RT reaction consisted of $1 \mu \mathrm{g}$ of RNA, $2 \mu \mathrm{l}$ of $5 \times \mathrm{RT}$ Buffer, $0.5 \mu \mathrm{l}$ of primer mix, $0.5 \mu \mathrm{l}$ of RT Enzyme Mix and $6 \mu \mathrm{l}$ of nuclease-free water in a total volume of $10 \mu \mathrm{l}$. Reactions were performed in an Eppendorf PCR System (Eppendorf, Germany) for $15 \mathrm{~min}$ at $37^{\circ} \mathrm{C}$, followed by heat inactivation for $5 \mathrm{~min}$ at $95^{\circ} \mathrm{C}$. Then, the $10 \mu \mathrm{RT}$ reaction mix was held at $-20^{\circ} \mathrm{C}$.

A 480 II Real-time PCR Instrument (Roche, Basel, Switzerland) was used with a $20 \mu \mathrm{l}$ PCR reaction mixture that included $2 \mu \mathrm{l}$ of cDNA, $10 \mu \mathrm{l}$ of $2 \times$ LightCycler ${ }^{\circledR}$ 480 SYBR Green Realtime PCR Master Mix (TOYOBO, Japan), $0.8 \mu \mathrm{l}$ of forward primer, $0.8 \mu \mathrm{l}$ of reverse primer and $6.4 \mu \mathrm{l}$ of nuclease-free water. Reactions were incubated in a 96-well optical plate (Roche) at $95^{\circ} \mathrm{C}$ for 30 seconds; followed by 40 cycles of $95^{\circ} \mathrm{C}$ for 5 seconds, $55^{\circ} \mathrm{C}$ for 10 seconds, and $72^{\circ} \mathrm{C}$ for 15 seconds. Each sample was run in triplicate for analysis. At the end of the PCR cycles, melting curve analysis was performed to validate the specific generation of the expected PCR product. All experiments were done in triplicate. The expression levels of RNAs were normalized to glyceraldehyde-3-phosphate dehydrogenase (GAPDH) and were calculated using the $2^{-\Delta \Delta \mathrm{Ct}}$ method [22]. The primer sequences were designed in the laboratory and synthesized by Sangon Biotech (Sangon, Shanghai, PRC).

\section{Western blotting}

Cells were collected and lysed in RIPA buffer supplemented with $1 \%$ PMSF. Protein was separated on a $12 \%$ sodium dodecyl sulfate-polyacrylamide gel electrophoresis (SDS-PAGE) gel and subsequently transferred to polyvinylidene difluoride (PVDF) membranes (Millipore Corp, Atlanta, GA, US). After blocking with 5\% non-fat dry milk, the PVDF membranes were incubated with the following primary antibodies overnight at $4{ }^{\circ} \mathrm{C}$ : rabbit polyclonal anti-GRP78 (Abcam, MA, USA), anti-CHOP (Santa Cruz, CA, USA), antiGAPDH (Proteintech, IL, USA), anti-Bcl-2 (Santa Cruz, CA, USA), anti-Bax (Santa Cruz, CA, USA). Membranes 
were incubated with an IRDyeTM 700DX -conjugated secondary antibody, Donkey Anti-Rabbit IgG (H+L) (LICOR, NE, USA), at room temperature for $1 \mathrm{~h}$. The signal was detected and analyzed by a LI-COR Odyssey infrared imaging system.

\section{Statistical analysis}

All statistical analyses were performed using GraphPad software (GraphPad Prism 6, GraphPad Software, La Jolla, CA, USA). The differences between groups were compared by using Student's t-test for all in vitro studies. A $\mathrm{p}<0.05$ was considered significant (* $\left.\mathrm{p}<0.05,{ }^{* *} \mathrm{p}<0.01,{ }^{* * *} \mathrm{p}<0.001\right)$.

\section{Abbreviations}

MCD, macular corneal dystrophy; WT, wild type; MT, mutation type; CHST6, carbohydrate sulfotransferase; C-GlcNAc6ST, corneal glucosamine N-acetyl-6-sulfotransferase; KS, keratan sulfate; Bcl-2, B-cell lymphoma-2; Bax, Bcl-2 Associated X Protein; ER, endoplasmic reticulum; GRP78, glucoseregulated protein 78; CHOP (CCAAT-enhancer-binding protein homologous protein); GAPDH, glyceraldeyde3-phosphate dehydrogease; ORF, open reading frame; PAPS, 3'-phospho-5'-adenylyl sulfate; PMSF, phenylmethylsulfonyl uoride; CCK-8, Cell Counting Kit-8; qPCR, quantitative real-time Polymerase Chain Reaction; TUNEL, terminal deoxynucleotidyl transferasemediated dUTP-biotin nick end labeling assay; HE, Hematoxylin and eosin, PAS, periodic acid-Schiff; PBS phosphate-buffered saline; EM, electron microscopy; EDTA, Ethylene Diamine Tetraacetie Acid; DMEM/F12, Dulbecco's Modified Eagle Media: Nutrient Mixture F-12; PI, propidium iodide; PVDF, polyvinylidene difluoride; SDS-PAGE, sodium dodecyl sulfate-polyacrylamide gel electrophoresis.

\section{Author contributions}

LYW and PL designed the experiments. LYW performed the experiments. LYW and XLT collected clinical data and tissue samples. LYW, XLL, ECS, DLW and CLW analyzed the experimental data. LYW, PL, and XLT wrote the manuscript.

\section{CONFLICTS OF INTEREST}

The authors declare no conflicts of interest.

\section{FINANCIAL SUPPORT}

This work was supported by the General Programs of National Natural Science Foundation of China (81470618), the Scientific Research Fund of Heilongjiang
Province Health Bureau (2011-031) and the Scientific Research Fund of Heilongjiang Province Education Department (12521262).

\section{REFERENCES}

1. Weiss JS, Møller HU, Lisch W, Kinoshita S, Aldave AJ, Belin MW, Kivel“ T, Busin M, Munier FL, Seitz B. The IC3D classification of the corneal dystrophies. Cornea. 2008; 228: S1-83.

2. Midura RJ, Hascall VC, Maccallum DK, Meyer RF, Thonar EJ, Hassell JR, Smith CF, Klintworth GK. Proteoglycan biosynthesis by human corneas from patients with types 1 and 2 macular corneal dystrophy. J Biol Chem. 1990; 265: 15947-55.

3. Klintworth GK, Oshima E, Al-Rajhi A, Al-Saif A, Thonar EJ, Karcioglu ZA. Macular corneal dystrophy in Saudi Arabia: a study of 56 cases and recognition of a new immunophenotype. Am J Ophthalmol. 1998; 125: 417.

4. Edward DP, Thonar EJ, Srinivasan M, Yue BJ, Tso MO. Macular dystrophy of the cornea. A systemic disorder of keratan sulfate metabolism. Ophthalmology. 1990; 97: 1194-200.

5. Saito T, Nishida K, Nakayama J, Akama TO, Fukuda MN, Watanabe K, Quantock AJ, Maeda N, Watanabe H, Tano Y. Sulfation patterns of keratan sulfate in different macular corneal dystrophy immunophenotypes using three different probes. Br J Ophthalmol. 2008; 92: 1434.

6. Akama TO, Nishida K, Nakayama J, Watanabe H, Ozaki K, Nakamura T, Dota A, Kawasaki S, Inoue Y, Maeda N, Yamamoto S, Fujiwara T, Thonar EJ, et al. Macular corneal dystrophy type I and type II are caused by distinct mutations in a new sulphotransferase gene. Nat Genet. 2000; 26: 237-41.

7. Cornuet PK, Blochberger TC, Hassell JR. Molecular polymorphism of lumican during corneal development. Invest Ophthalmol Vis Sci. 1994; 35: 870.

8. Musselmann K, Hassell JR. Focus on molecules: CHST6 (carbohydrate sulfotransferase 6; corneal $\mathrm{N}$-acetylglucosamine-6-sulfotransferase). Exp Eye Res. 2006; 83: 707-8.

9. Ong E, Yeh JC, Ding Y, Hindsgaul O, Pedersen LC, Negishi M, Fukuda M. Structure and function of HNK-1 sulfotransferase. Identification of donor and acceptor binding sites by site-directed mutagenesis. J Biol Chem. 1999; 274: 25608-12.

10. Kakuta Y, Pedersen LG, Pedersen LC, Negishi M. Conserved structural motifs in the sulfotransferase family. Trends Biochem Sci. 1998; 23: 129-30.

11. Birgani SA, Salehi Z, Houshmand M, Mohamadi MJ, Promehr LA, Mozafarzadeh Z. Novel mutations of CHST6 in Iranian patients with macular corneal dystrophy. Mol Vis. 2009; 15: 373.

12. Yaylacioglu TF, Kayman KG, Guntekin ES, Pasaoglu OT, Akata RF, Dincer PR. Genetic analysis of CHST6 and 
TGFBI in Turkish patients with corneal dystrophies: Five novel variations in CHST6. Mol Vis. 2016; 22: 1267.

13. El-Ashry MF, Abd El-Aziz MM, Shalaby O, Bhattacharya SS. Molecular genetic study of Egyptian patients with macular corneal dystrophy. Br J Ophthalmol. 2010; 94: $250-5$.

14. Liu Z, Tian X, Iida N, Fujiki K, Xie P, Wang W, Ma Z, Kanai A, Murakami A. Mutation analysis of CHST6 gene in Chinese patients with macular corneal dystrophy. Cornea. 2010; 29: 883-8.

15. Szentm'ry N, St“ndl A, Szende B, S*veges I. P21, p27, bax, cathepsin and survivin pathways in macular dystrophy corneas. Histol Histopathol. 2010; 25: 287-90.

16. Szentm'ry N, Tak'cs L, Berta A, Szende B, S“veges I, $\mathrm{M}^{\prime}$ 'dis L. Cell proliferation and apoptosis in stromal corneal dystrophies. Histol \& Histopathol. 2007; 22: 837-45.

17. Szentm'ry N, Seitz B, Langenbucher A, Schl“tzerschrehardt U, Hofmannrummelt C, Naumann GO. Histologic and ultrastructural changes in corneas with granular and macular dystrophy after excimer laser phototherapeutic keratectomy. Cornea. 2006; 25: 257-63.

18. Paliwal P, Sharma A, Tandon R, Sharma N, Titiyal JS, Sen $\mathrm{S}$, Vajpayee RB. Molecular genetic analysis of macular corneal dystrophy patients from North India. Ophthalmic Res. 2012; 48: 28-32.

19. Hetz C. The unfolded protein response: controlling cell fate decisions under ER stress and beyond. Nat Rev Mol Cell Biol. 2012; 13: 89.

20. Chen M, Ma G, Yue Y, Wei Y, Li Q, Tong Z, Zhang L, Miao G, Zhang J. Downregulation of the miR-30 family microRNAs contributes to endoplasmic reticulum stress in cardiac muscle and vascular smooth muscle cells. Int J Cardiol. 2014; 173: 65-73.

21. Zinszner H, Kuroda M, Wang X, Batchvarova N, Lightfoot RT, Remotti H, Stevens JL, Ron D. CHOP is implicated in programmed cell death in response to impaired function of the endoplasmic reticulum. Genes Dev. 1998; 12: 982.

22. Adams J, Cory S. The Bcl-2 apoptotic switch in cancer development and therapy. Oncogene. 2007; 26: 1324-37.

23. Karpel-Massler G, Ishida CT, Bianchetti E, Shu C, PerezLorenzo R, Horst B, Banu M, Roth KA, Bruce JN, Canoll P. Inhibition of mitochondrial matrix chaperones and anti-apoptotic Bcl-2 family proteins empower antitumor therapeutic responses. Cancer Res. 2017. https://doi. org/10.1158/0008-5472.CAN-16-3424.

24. Daniele S, Pietrobono D, Costa B, Giustiniano M, La PV, Giacomelli C, La RG, Silvestri R, Taliani S, Trincavelli ML. Bax activation blocks self-renewal and induces apoptosis of human glioblastoma stem cells. ACS Chem Neurosci. 2017. https://doi.org/10.1021/acschemneuro.7b00023.

25. Oakes SA, Scorrano L, Opferman JT, Bassik MC, Nishino M, Pozzan T, Korsmeyer SJ. Proapoptotic BAX and BAK regulate the type 1 inositol trisphosphate receptor and calcium leak from the endoplasmic reticulum. Proc Natl Acad Sci U S A. 2005; 102: 105.

26. Reed JC. Proapoptotic multidomain Bcl-2/Bax-family proteins: mechanisms, physiological roles, and therapeutic opportunities. Cell Death Diff. 2006; 13: 1378.

27. Kim H, Tu HC, Ren D, Takeuchi O, Jeffers JR, Zambetti GP, Hsieh JJ, Cheng EH. Stepwise activation of BAX and BAK by tBID, BIM, and PUMA initiates mitochondrial apoptosis. Mol Cell. 2009; 36: 487-49.

28. Yan X, Jiang Z, Bi L, Yang Y, Chen W. Salvianolic acid A attenuates TNF- $\alpha$ - and D-GalN-induced ER stress-mediated and mitochondrial-dependent apoptosis by modulating $\mathrm{Bax} / \mathrm{Bcl}-2$ ratio and calcium release in hepatocyte LO2 cells. Naunyn Schmiedebergs Arch Pharmacol. 2015; 388: 817-30.

29. Holbrook J, Neu-Yilik G, Hentze M, Kulozik AE. Nonsense-mediated decay approaches the clinic. Nat Genet. 2004; 36: 801-8.

30. Wang L, Luo R, Fu P, Huang C. Epoxomicin induces endoplasmic reticulum stress protein GADD153 / CHOP to promote cell apoptosis in prostate cancer DU145 cells. J Third Mil Med Univ. 2014; 23: 2367-5.

31. Puthalakath H, O'Reilly LA, Gunn P, Lee L, Kelly PN, Huntington ND, Hughes PD, Michalak EM, MckimmBreschkin J, Motoyama N. ER stress triggers apoptosis by activating BH3-only protein Bim. Cell. 2007; 129: 1337-49.

32. Lee S, Kim S, Hwang S, Cherrington NJ, Ryu DY. Dysregulated expression of proteins associated with ER stress, autophagy and apoptosis in tissues from nonalcoholic fatty liver disease. Oncotarget. 2017; 8: 63370-81. https:// doi.org/10.18632/oncotarget.18812. 